\title{
Erratum to: Nursing home-acquired pneumonia presenting at the emergency department
}

\author{
Rui Pereira $^{1}$ (D) $\cdot$ Sara Oliveira ${ }^{2} \cdot$ André Almeida $^{2}$
}

Published online: 31 October 2016

(c) SIMI 2016

\section{Erratum to: Intern Emerg Med (2016) 11:999-1004 DOI 10.1007/s11739-016-1412-z}

In the original publication, Centro de Investigação CHLC unit name was missed to include in the Acknowledgments section.

The complete Acknowledgments section should read as:

The authors would like to thank for the contribution of Ana Catarina Patrício, Filipa Silva, Joana Ferreira, Pedro la Féria, Pedro Silva, João Oliveira, Lara câmara, Rui Malheiro, Rodrigo Leão, Mário Silva, Pedro Russo, Ana Lladó and Paulo Barreto. Also the authors would like to thank the Epidemiology and Statistics Office of the Research Unit, Centro Hospitalar de Lisboa Central for their contribution.

The online version of the original article can be found under doi:10.1007/s11739-016-1412-z.

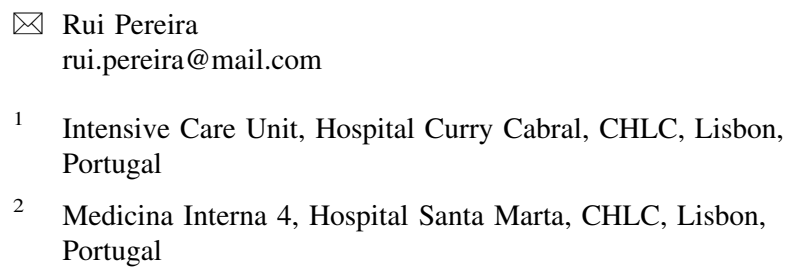

